\title{
Conflict, Settlement, and the Shadow of the Future*
}

\author{
Michael McBride ${ }^{\dagger}$ \\ Department of Economics \\ University of California, Irvine \\ Stergios Skaperdas \\ Department of Economics \\ University of California, Irvine \\ This version: March 12, 2009
}

\begin{abstract}
In many instances of potential violent and non-violent conflict the future strategic positions of adversaries are very different when there is open conflict than when there is settlement. Then, as the future becomes more important, open conflict becomes more likely than settlement. We theoretically demonstrate this result and discuss its applicability in war, litigation, and other settings. We test for this effect in a laboratory experiment and find that subjects are more likely to engage in risky conflict as the shadow of the future increases.
\end{abstract}

JEL Classifications: C72, C91, D01, D74.

Keywords: conflict, litigation, property rights, folk theorem.

\footnotetext{
${ }^{*}$ We thank Michelle Garfinkel, Gary Richardson, and seminar participants at Loyola Marymount University, participants in the Economic Science Insitute seminar at Chapman University, attendees at the "Rationality and Conflict" conference at Yale University, and participants at the UC Irvine Theory, History, and Development Seminar for valuable comments. For financial support we are grateful to the Center for the Study of Democracy and the Center for Global Peace and Conflict Studies, both at UC Irvine.

†3151 Social Science Plaza, Irvine, CA, 92697-5100, mcbride@uci.edu, sskaperd@uci.edu.
} 


\section{Introduction}

It is difficult to understand conflict from an economic perspective, whether it is the violent conflict of war or the non-violent conflict of going to court or on strike. For, ideally, the inefficiencies that can take place under conflict could conceivably be reduced, if not eliminated altogether, by some appropriate Coasian transfers. The one type of explanation of conflict that has largely dominated the economics literature is that of incomplete or asymmetric information of one party about the preferences, endowments, available strategies, or other characteristics of another party. (See, for example, Brito and Intriligator, 1985, and Bester and Warneryd, 2006.) In the presence of such information asymmetries - and the presumed inability of each side to credibly reveal the truth about itself to other parties - there can be states of the world in which one or more parties will choose conflict rationally, as part of some reasonable equilibrium concept. ${ }^{1}$

Whereas asymmetric information is undoubtedly relevant in many instances of conflict, there is scope for types of explanation that may add to informational ones. In particular, there is another type of explanation for conflict that is potentially empirically important but has received very limited attention. There are two key ingredients to this explanation.

- First, adversaries cannot write long-term contracts on an "enforcement" variable, like on arms or hiring lawyers to prepare for possible future litigation. However, the adversaries can write short-term contracts or settlements that are conditioned on such enforcement variables. Such settlements can be thought of as "cold wars" in the case of warfare and may involve the expenditure of substantial resources on enforcement so that each side maintains its bargaining position. That is, such settlements may be expensive to maintain.

- Second, conflictual outcomes have different long-term implications for the strength of

\footnotetext{
${ }^{1}$ Other reasons, based on economic models, that may induce conflict include indivisibilities, increasing returns in production, risk seeking preferences. For a review of reason for going to war primarily concernced with international relations see Fearon (1995) and for a review based on conflict models that allow for bargaining see Skaperdas (2006).
} 
each adversary than peaceful settlement outcomes have. For example, the winner of a war could be expected to gain more resources, and therefore a strategic advantage, relative to the loser well into the future, whereas a peaceful settlement outcome would not be expected to have as dramatic a change in the future strategic positions of the adversaries. Similarly, going to court can be expected to enhance the property rights of the winner of a legal dispute and diminish those of the loser, whereas an out-of-court settlement keeps the relative position of litigants more constant.

Under these two conditions, conflict can be an equilibrium outcome even when it brings about destruction and has other costs compared to settlement. The reason is that the future strategic advantage conferred on the winner would typically reduce the future costs of enforcement that would have to be incurred compared to settlement. In the limiting case in which the winner wins forever, no costs are incurred in the future. In the case of war the winner would not have to pay the costs of a cold war, whereas in the case of litigation the winner, whose property rights have been strengthened, would lower or eliminate the fees paid to lawyers. For the case of war, Fearon (1995) first discussed this type of explanation, and models that make the argument explicit include a finite-horizon model in Garfinkel and Skaperdas (2000) and infinite-horizon models in Powell (2006) and McBride and Skaperdas (2007). ${ }^{2}$ Similarly, Robson and Skaperdas (2008) show how going to court in the case of legal disputes can be an equilibrium outcome.

One robust finding in such environments is that conflict becomes more likely and settlement less likely as the discount factor of the adversaries becomes larger or, to use a more evocative term, as the shadow of the future becomes longer. A longer shadow of the future makes the valuation of future payoffs higher relative to current payoffs, and the future re-

\footnotetext{
${ }^{2}$ Powell (1993) was the first dynamic model that included similar considerations (and the main comparative static result regarding the "shadow of the future") but did not include the possibility of within-period transfers between adversaries. That is, there is a within-period indivisibility in Powell's model, something that is an analytically distinct reason for conflict. However, there is no reason that Powell's (1993) model could be not be adapted to allow for within-period transfers and still yield conflict as a possible equilibirum outcome. Jackson and Morelli (2008) analyze a dynamic model similar to that of Powell and allow for mixed strategies, with conflict taking place for at least some realizations of mixed-streategy equilibria.
} 
wards of an enhanced strategic position under conflict then loom larger than the settlement payoffs that involve enforcement expenditures well into the future. Moreover, enforcement expenditures also typically become higher when the future becomes more important ${ }^{3}$ and since the winner of a conflict can lower or completely eliminate these expenditures in the future this is an analytically distinct reason for conflict being induced as a result of lower discounting of the future.

The effect of discounting highlighted above is obviously opposite of that implied by folktheorem arguments. However, the opposite effects that are found in the two approaches are not incompatible. On the one hand, the settings that we examine are fundamentally non-stationary and exhibit time dependence, in the sense that open conflict leads to potentially radically different strategic settings in the future than settlement does. On the other hand, the supergame strategies that sustain cooperation (or peace) are typically adopted in stationary environments in which the same stage game is repeated over time and conflict does not change the relative strategic positions of adversaries in the future. Whereas such settings are stationary, the supergame strategies themselves are time-(or history-) dependent so as to bring about the possibility of cooperation by the threat of future punishments in the event of conflictual choices in the present. More fundamentally, however, even if we were to allow for supergame strategies in our setting, the outcomes that such strategies would implement would be such that expenditures on arming or litigation (that is, the level of enforcement expenditures) could be partially or completely eliminated so as to achieve complete "cooperation" or "peace" that involves partial or complete disarmament. Such a possibility would help us understand how disarmament might come about in the long run, but it does not illuminate the reasons for engaging in conflict when disarmament is not possible but settlements in the shadow of conflict - through appropriate short-term transfers - are possible. In short, a folk-theorem argument applied to our setting could illuminate

\footnotetext{
${ }^{3}$ In addition to the papers mentioned above, Powell (1993), Skaperdas and Syropoulos (1996), and Mehlum and Moene (2007) also show how enforcement costs increase with higher discount factor when there is conflict, even though none of these papers allow for settlement.
} 
why complete, long-term peace and disarmament might come about, whereas our argument clarifies why conflict may occur in the absence of disarmament.

After elaborating on the empirical relevance of our argument in section 2, section 3 develops an illustrative model on which our experiment is based. The model yields the key prediction that conflict is the equilibrium outcome when discount factors are higher than a critical level. Particular extensions and elaborations of the model, provided in the Appendix, illustrate how the main prediction is robust to changes in the adversaries' environment and the particular types of conflict they face. Section 4 discusses the experiment design and results. Our subjects faced a choice between a certain payoff from settlement or the uncertain outcome of a conflict. The shadow of the future is approximated by a constant continuation probability of the same game. In this last feature of the experiment we have followed Dal Bó (2005), who has examined the effects of the shadow of the future in stationary environments in which the folk theorem applies. ${ }^{4}$ We find a clear tendency for a longer shadow of the future to increase the subjects' choice of conflict, especially compared to the one-shot case with zero continuation probability.

\section{The Context: Going to Court, Engaging in War, and Other Conflictual Settings}

The two necessary elements of the explanation of conflict we examine in this paper are (i) the impossibility of writing long-term contracts on enforcement levels and (ii) conflict and settlement have very different dynamic paths in terms of the initial conditions that adversaries face in the future. Condition (i) is very likely to be satisfied both in adversarial settings that can lead to war and in legal disputes. The main enforcement variable in wars is arming and in many cases it is impossible to write long-term disarmament contracts (although, it is typ-

\footnotetext{
${ }^{4}$ We are unaware of any experimental studies that involve conflict explicitly in dynamic settings. Durham, Hirshleifer, and Smith (1996) provide experimental evidence of a static model of conflict like that of Hirshleifer (1991) which is also similar to a stage game of the dynamic model in Appendix A. Abbink and Brandts (2009) study experimentally the choice between conflict and settlement in a static setting when settlement is always efficient.
} 
ically possible as well as a frequent occurrence to have truces and cold wars - thought of as a series of short-term contracts - that are enforceable by each adversary's military strength). In legal disputes the main enforcement variable involves litigation expenditures on lawyers, paralegals, private investigators, or potential expert witnesses, and it is similarly difficult to write long-term contracts that would prevent potential legal adversaries from engaging in any such expenditures. However, the retention of lawyers and the threat to deploy them in court could help enforce shorter-term out-of-court settlements.

We next discuss why condition (ii) is plausible in many circumstances and why the type of explanation we examine in this paper is promising.

\subsection{Legal Disputes}

As is the case with wars, information problems are considered the primary reason for legal disputes ending up in court (see, for example, Hay and Spier, 1998). However, going to court and settling out of court can have significantly different implications for the relative future strategic positions of potential litigants.

On the one hand, going to court enhances the strategic position of the winner and increases his chance of prevailing in similar future disputes with the same or different adversaries. Conversely, the loser has a diminished future strategic position to prevail in similar disputes. In other words, going to court and obtaining a decision enhances the property rights of the winner and diminishes those of the loser well into the future.

On the other hand, settling out of court tends to leave the relative property rights positions of adversaries in the future more stable, though not necessarily constant. Settling out of court with someone who has sued you could invite future litigants who might sue you solely in order to extract an out-of-court settlement. Therefore, going to court, though costly in the short-run, could deter future litigation and the costs that would accompany such litigation. Moreover, in many legal systems the holder of an asset who does not periodically exercise some form of open demonstration of ownership, including possibly receiving 
a positive court decision, could lead to the loss of the asset or at least the "atrophying" of his or her property right over that asset (Buchanan, 1989).

Thus, going to court enhances property rights whereas not doing so might erode one's property right. Indeed, going to court can be an equilibrium outcome, even in the absence of any informational problems, when it is necessary to ensure future property rights.

\subsection{Wars}

For disputes that could potentially lead to war it is evident that war affects the adversaries' future strategic positions differently than does a truce or peace. Winners can obtain a better future strategic position that they had prior to war, and losers typically have a worse strategic position than prior to war. In the absence of war, strategic positions do not change much, although one side's power may be declining over time while the other side's power might be ascending because of economic, demographic, or other reasons.

Clearly, informational problems can help explain many wars. However, there is no reason to think that all wars in all of their aspects must be due solely to such problems. We briefly offer some examples in which our hypothesis is relevant and identify some aspects of warfare difficult to explain with informational failures.

Since the Second World War, civil wars have been much more common than interstate wars. With an average duration of over seven years (Collier et. al., 2003), by that time both informational asymmetries and the costs of war become apparent. Similarly, civil wars within Northern Italian city-states in late medieval times often lasted for decades with tremendous costs to the participants (see, for the case of Genoa, Ch.8 in Greif, 2006). Before attributing all such conflicts to informational problems, the gamble on gaining long-term advantage over opponents appears as at least another, complementary to others, explanation of the many civil wars that have occurred. Moreover, in many cases it can me argued that many key pariticipants in ethnic and religious conflict tend to value the future highly, because of their close identification with the future of their ethnic group or with religious salvation, and 
thus contribute to the intensification of conflicts and the difficulties in achieving peaceful settlements.

World War I is frequently mentioned as a war that started because of information problems (see, for example, Ch. 2 in Joll, 1992). Incompleteness of information might not be the whole story, however, if we were to consider that there was no peace after it became obvious to almost everyone that trench warfare brought stalemate and not quick victory. With trench warfare much of the initial incomplete information dissipated, the costs of the war continuing were horrendous with no end in sight, and yet war continued. Reasonably, it could be argued that each side saw the chance of eventual dominance well into the future as the carrot that kept the war going, and that all major adversaries had long-term strategic objectives that made them arm in the first place. At least some fraction of the elites within each of the major states involved saw a war as necessary for the defense of existing possessions or repossession of old ones close to them (like Alsace and Lorraine for France and Germany) or for the defense or capture of areas around the globe.

Also, relevant to our approach was the endgame of World War II. Why didn't the United States settle for the advantageous peace for which Japan was bidding? Why did the Soviet Union push so hard, and at such cost, in the Eastern front? Why were the Western allies rushing in the Western front? Certainly it could not be because they were not aware of Japan's or Germany's strength or the other way around. The allies were all looking into the future. They wanted the Axis powers crushed without the possibility of even a remote comeback, as it happened with Germany after World War I. They were also eyeing one another, jockeying for position in the post-war period. The Cold War had effectively started considerably before the end of the actual hot war.

\subsection{Other Types of Conflict}

In addition to warfare and litigation, there are other types of disputes that could be relevant for the approach we develop here. They include rent-seeking and related policy disputes, 
labor union and firm disputes, and possibly competition among firms that use marketing and advertising as major instruments of competition. For the case of rent-seeking and other policy disputes, the relevant enforcement variables are expenditures on lobbying and related activities that are clearly not contractible in the long-run. Settlement in this case would imply that the major sides to the policy dispute agree on a compromise proposal, whereas conflict would involve each side offering clearly different proposals, not compromising, and letting the lobbying and legislative process determine which proposal is eventually adopted.

For the case of disputes between labor unions and firms, the non-contractible variables would include the expenditures on the part of the union on strike preparation (including possibly the accumulation of a strike fund) and for the firms the resources expended on negotiation and preparations for a strike or a lockout. Conflict in this case would involve a strike or a lockout, whereas settlement would involve the signing of a new contract for a set period of time. For the case of competing firms, the non-contractible enforcement variable could be the resources expended on marketing and advertising, whereas conflict would be equivalent to a price war and settlement a more cooperative outcome on their part. In all these cases, the conflictual and settlement outcomes can bring about different future strategic position for the adversaries, and therefore our approach and the effect of the shadow of the future can be important for bringing about conflict or settlement. However, we do not pursue these applications further as the literature and applications do not appear to our knowledge to be as developed.

\section{An Illustrative Model: Conflict vs. Settlement}

Consider two agents, $A$ and $B$, who interact over an indefinite horizon. In each period they compete over a prize of value $Y$. Because the two agents cannot write contracts on the ultimate source of enforcement each period they have to expend resources $e_{A}$ and $e_{B}$ to maintain their position. These expenditures are necessary regardless of whether Conflict or Settlement (under the threat of conflict) ultimately prevails. In the case that Conflict 
involves actual warfare, $e_{A}$ and $e_{B}$ would represent arming expenditures, and the two agents could be parties in a domestic dispute that could lead to civil war or adversarial states. In the case of litigation $e_{A}$ and $e_{B}$ would represent expenditures on lawyers' and related fees, and the two agents could be two parties that have property claims on a productive asset which they could exploit jointly without going to court or they could go to court and resolve their claims once and for all. (In Appendix B, we examine another model of litigation that involves a long-term agent who faces the potential of being sued for damages in each period by a series of short-term agents.)

In the event of Conflict, the enforcement expenditures $e_{A}$ and $e_{B}$ affect the probabilities of winning for each side; we denote these probabilities by $q_{A}$ and $q_{B}$. We suppose that one agent's enforcement expenditures positively affect his own winning probability and negatively affect his opponent's winning probability. As our experiments do not involve an endogenous choice of these expenditures, we do not endogenize them here, although as we show in Appendix A that the main comparative static results are, if anything, strengthened when enforcement expenditures are chosen endogenously. Models of conflict that examine the endogenous determination of arming in static settings include Hirshleifer (1991) and Esteban and Ray (1999, 2008), whereas models dedicated to litigation have been examined by Farmer and Pecorino (1999) and Hirshleifer and Osborne (2001). In the case of Settlement, $e_{A}$ and $e_{B}$ - through their effect on the probabilities of winning in the event of Conflict - influence each agent's bargaining position in arriving at a particular deterministic settlement (shares of the prize $Y)$.

If Conflict were to take place only a fraction $\phi \in(0,1)$ of $Y$ can be consumed with the rest, $(1-\phi) Y$, being destroyed by the conflict. In each period, then, the expected single-period payoff of agent $i=A, B$ in the event of Conflict is

$$
U_{i}^{c}=q_{i} \phi Y-e_{i} .
$$

Given that Conflict is destructive, in each period both sides would prefer to divide $Y$ in shares that equal their winning probabilities because it would result in a payoff of $q_{i} Y-e_{i}>$ 
$q_{i} \phi Y-e_{i}=U_{i}^{c}$. A range of other possible divisions of $Y$ would also be Pareto superior to the expected payoffs under Conflict. With an indefinite repetition of such single-period interactions, there would never be an incentive to induce Conflict, provided the two agents could costlessly communicate and the prize $Y$ were divisible.

Nevertheless, if Conflict were to occur, we would reasonably expect interactions between the two agents to be different in the future. The winner may have eliminated the loser's ability to carry out war in the future, or he could command more resources conducive to waging war than the loser in the future. In effect, conflict biases future conflicts even further in favor of today's winner. Such induced asymmetries could well make Conflict an attractive possibility by trading off a lower expected payoff today for higher payoffs in the future.

For simplicity, we allow a stark and simple form of dependence of future power on today's Conflict. We suppose that the loser of Conflict in any period would be unable to raise the resources that are necessary to challenge the winner in future periods and, thus, the winner would be able to enjoy the prize $Y$ in all future periods whereas the loser receives nothing. (McBride and Skaperdas, 2007, illustrate how the main results extend to the less stark setting in which for an agent to drop completely out of contention there is a series of small conflicts with probabilistic outcomes, and not just one, that would have to be lost.)

Next, consider the negotiations that would result in either Settlement or Conflict in any particular period in which no Conflict has occurred in the past and the agents have already expended resources on enforcement (i.e., e's have been expended and represent sunk costs). Further, and without loss of generality, suppose agent $A$ is the one that has the initiative in making a proposal. In the case of Settlement, the agent would receive the whole value of $Y$ and would make an offer of subsidy $S$ to agent $B$, which would either accept or reject $A$ 's offer. If the offer is rejected, Conflict ensues. The resources that each party has invested on enforcement are considered sunk so that they play no more in current negotiations.

Assuming a discount factor $p \in(0,1),{ }^{5}$ the discounted expected payoff for agent $i=A, B$

\footnotetext{
${ }^{5}$ Given risk neutrality, could also be interpreted as the constant probability of the game continuing in each period, an interpretation that we maintain in the experiments.
} 
in the event of Conflict is the following:

$$
V_{i}^{C}=q_{i} \phi Y+q_{i} \sum_{t=1}^{\infty} p^{t} Y+\left(1-q_{i}\right) \sum_{t=1}^{\infty} p^{t} 0=q_{i}\left(\phi+\frac{p}{1-p}\right) Y .
$$

Note how in the event of Conflict, because one agent would be eliminated from contention, in the future no resources would be devoted to enforcement. Agent $B$ would accept any offer $S$ from agent $A$ that satisfies inequality

$$
S+p V_{B}(S) \geq V_{B}^{C}
$$

where $V_{B}(S)$ denotes the continuation payoff of agent $B$ when she is a responder given the subsidy $S$. As part of any Markov Perfect Equilibrium in which a positive subsidy is given, agent $A$ would offer a subsidy $S^{*}$ that satisfies (3) as an equality. Assuming that $S^{*}$ would be accepted in this period, it would be acceptable in all future periods and therefore $V_{B}\left(S^{*}\right)=\frac{S^{*}-e_{B}}{1-p}$. Then, from (3) and (2), the subsidy would be

$$
S^{*}=q_{B}[\phi(1-p)+p] Y+p e_{B}
$$

Note that this Conflict-deterring subsidy from $A$ to $B$ depends positively on the power of agent $B$ (as proxied by her probability of winning $q_{B}$ ), on the share of output that is not destroyed in the event of Conflict, on the discount factor, as well as on the value of the prize $Y$. However, this minimally acceptable subsidy to agent $B$ might not be in agent $A$ 's interest to offer. In particular, agent $A$ will only make this offer if the expected payoff under Settlement exceeds that under Conflict,

$$
Y-S^{*}+p V_{A}\left(S^{*}\right) \geq V_{A}^{C}
$$

where $V_{A}\left(S^{*}\right)=\frac{Y-S^{*}-e_{A}}{1-p}$ is the continuation payoff of agent $A$ if Settlement were to prevail forever. Supposing the probabilities of winning for the two sides sum to one (i.e. $q_{A}+q_{B}=1$ ), it is straightforward to show that the condition for Settlement (so that (3) and (5) are both satisfied) is as follows:

$$
\frac{p\left(e_{A}+e_{B}\right)}{(1-\phi)(1-p)} \leq Y
$$


If this inequality holds, there is a feasible and optimal subsidy that makes Settlement preferred to Conflict. Alternatively, based on (6), Conflict is more likely and Settlement is less likely, the lower is the contested output $Y$; the higher are the resources devoted to arming $\left(e_{A}+e_{B}\right)$ by the two agents; the less destructive is Conflict (or, the higher is $\phi$ ); and, the higher is the discount factor $p$ (i.e., the game's constant continuation probability). In terms of the main variable of interested, for any combination of the other parameters such that

$$
p>p^{*}=\frac{Y(1-\phi)}{e_{A}+e_{B}+Y(1-\phi)},
$$

then the equilibrium outcome is Conflict.

It is this last effect of the "shadow of the future" that we test experimentally. In Appendix A and B we show the robustness of this effect in different settings. In Appendix A, we endogenize the enforcement efforts $e_{A}$ and $e_{B}$. In Appendix B, we provide a model of a legal dispute involving a long-term agent against a series of short-term agents who could potentially sue the long-term agent for damages.

Though this shadow of the future effect seems to counter the standard Folk Theorem intuition of less conflict with higher discount factors, we emphasize that the two logics are orthogonal. Supergame strategies (e.g., trigger strategies) can sustain peace in stationary environments when conflict today does not impact the relative positions of the actors tomorrow. We argue that conflict produces a non-stationarity that is not well-represented by a standard repeated game. In effect, conflict means that the game played tomorrow is not the same (stage) game that was played today. Thus, Folk Theorem intuition is correct and valid in stationary environments, but the opposite shadow of the future effect that we propose here will apply to settings where conflict changes future interactions in favor of the winner.

It can be shown that Conflict is the individually rational choice in our benchmark model exactly when it maximizes the sum of expected payoffs of the two players. One might thus 
claim that Conflict is efficient - at least from the point of view of the two rivals - in this model. We note, however, that this conclusion ignores the possible negative externalities of Conflict. For example, it will likely be the case that bystanders are severely and adversely affected by Conflict, and their well-being, insofar as it does not affect the two rivals' expected payoffs, will not be factored into the two rivals' utility functions. It would not be appropriate to call Conflict efficient in this setting. However, in other settings, it might be appropriate to call Conflict efficient. For example, if going to court can definitively resolve a property rights dispute, then it can save both parties immense costs of challenging and protecting those rights in the future. Going to court can thus be seen as socially efficient in at least some settings.

\section{An Experiment: Conflict vs. Settlement}

\subsection{Experiment Design}

Our experiment consists of three sessions conducted at the California Social Science Experimental (CASSEL) Laboratory at UCLA. Each session used subjects recruited from the CASSEL subject pool database. After learning about the laboratory from advertisements or friends, a UCLA student registers in the subject pool through the laboratory's web site. All subjects in the pool were sent an email notifying them of an experiment session. An interested student then registers for a specific sessions; none participated in more than one session. To facilitate experiment management, instruction, and data collection, we conducted the experiment using specially designed software. Each subject accumulated "points" based on her choices, the choices made by her matched partner in a given round, and random draws by the computer. The more points earned, the more U.S. currency the subject received at the experiment session's end, with the exact amount determined by a publicly announce point-dollar exchange rate. Each subject also received a $\$ 5$ show-up payment. The average earned amount was $\$ 30$ for about 75 minutes of participation.

A Single Match. A single session consists of a number of matches (trials). Each 
match captures the reduced Settlement-or-Conflict decision scenario depicted in the model, the only difference being that, instead of having subjects choose the settlement amount as in the model above, we suppose Settlement involves an equal split of the surplus. The main comparative statics of the model are unchanged with this simpler exogenous Settlement amount, and this set-up is easier for subjects to understand.

In a single match, two subjects are paired and round one begins. Both are publicly told that the "point value" is 100 (prize $Y$ in Section 3's notation), the "standard fee" is 30 (arming cost $e=e_{A}=e_{B}=30$ ), the "flipping fee" is 30 (total destruction $(1-\phi) Y$ ), and the "continuation probability" (probability $p$ ) which takes three values (see below). Each subject then selects either "split" (Settlement) or "flip" (Conflict). Payments are then received according to the model presented earlier. That is, in round 1 each receives 20 $\left(=\frac{1}{2} Y-e\right)$ if both chose split; and if at least one chose flip, then a random draw by the computer selects one of the subjects to be the winner and the other to be the loser, where the winner's round 1 payment is $40(=\phi Y-e)$ and the loser's round 1 payment is -30 $(=-e)$. The computer then randomly determines whether the match continues to round 2. If both chose split in round 1 , then the round 1 settlement applies to any future rounds. Thus, should round 2 be reached, settlement in round 1 implies settlement in round 2, and each receives 20. If there was conflict in round 1, then the winner from round 1 receives 100 in round 2, and the loser in round 1 receives 0 in round 2. Any other future rounds, should they be reached, have the same payoff structure as round 2. Having each subject only make one choice per match (rather than making a choice in each round following peace) simplifies the decision process for the subjects, speeds up the experiment, and facilitates the making of hypotheses (see below).

Continuation Probability. The continuation probability $p$ is the key treatment variable as it reflects the shadow of the future. It takes one of three values: $0,0.5$, or 0.75 . A match lasts a single round if $p=0$. If $p=0.5$ or $p=0.75$, then the exact number of rounds in a given match is determined randomly by the computer. The expected number of rounds is 
2 under $p=0.5$ and 4 under $p=0.75$. Subjects are told the continuation probability at the same time they are told the other parameters - immediately prior to making the split-or-flip (Settlement-or-Conflict) decision. These values for $p$ were selected because, first, they are the same used by Dal Bó (2005), thereby providing a point of comparison with his study, and, second, they allow for sharp predictions as discussed below.

Rotation Matching. Dal Bó (2005) uses a rotation matching procedure "to avoid potential interaction and contagion effects between the different" matches (1596). In each session, subjects are divided into two equally-sized groups of agents: Blue and Red. In any given match, a Blue and Red are paired. In the next match, the Blue is matched with a different Red, and so on. One full rotation (also called a zipper) consists of each blue being paired exactly once with each Red. With 24 subjects split into Blue and Red groups each with 12 subjects, one rotation consists of 12 matches. With three treatment values for the continuation probability, we thus have 4 matches per treatment variable in one rotation. We use Dal Bó's rotation mechanism primarily for comparison with Dal Bó's design even though the contagion effects that might arise in his repeated game context are unlikely to be present in our setting. Contrary to the mixed-motive prisoner's dilemma game, the weakly dominant strategy in our setting yields the highest expected payoff ex ante, thus removing the incentive to play meta-strategies across matches.

Sessions. We conducted three sessions to consider how changes in the treatment variable may impact decisions. Session 1 uses one matching rotation (12 matches) with an ABC design: 4 matches of $p=0$, then 4 matches of $p=0.5$, and then 4 matches of $p=0.75$. We supposed that this order would be easiest for subjects. Session 2 uses one rotation with a CBA design: 4 matches of $p=0.75$, then 4 matches of $p=0.5$, and then 4 matches of $p=0$. The reverse order is meant to capture a priming effect. Session 3 uses two full rotations (24 matches) with an ABCCBA design: subjects do one full rotation akin to Session 1, are then reagented into Blues and Reds, and then do another full rotation akin to Session 2. Session 3 is meant to capture both the learning and priming effects. Table 1 summarizes 
basic information about the three sessions. The bottom panel of the table breaks Session 3 into its first and second matching rotations and calls them Sessions 3(a) and 3(b).

Instructions. After being seated at computers in the lab, the subjects were instructed in the basic payoff structure of the decision making environment, and then they participated in four practice matches. ${ }^{6}$ This instructional period was designed to familiarize subjects with both the computer user interface as well as the payoff structure and basic strategic environment.

Bankruptcy Prevention. Because losing a contest involves a net loss of 30 points, it is possible for subjects to lose points throughout the experiment. To prevent bankruptcy and the risk-loving behavior that may accompany it, each subject in Sessions 1 and 2 was given an initial 240 points. Because subjects in Session 3 participated in two matching rotations, they were given 240 points twice, once at the start of each rotation. No subject in any session experienced or came close to bankruptcy.

Questionnaire. After the last match but before leaving the laboratory, each subject filled out a questionnaire that asked for age, sex, major, year in school, number of economics courses taken, number of statistics courses taken, and so on. We use information from the questionnaire for rough qualitative comparisons of the subjects across sessions.

\subsection{Hypotheses}

Having one choice per match collapses the potentially infinitely repeated game, in expected payoff terms, into a simple $2 \times 2$ matrix normal form game. Figure $1(\mathrm{a})-(\mathrm{c})$ presents the matrix for each treatment value of the continuation probability. In each case, the setting is the Hi-Lo game depicted in Figure 1(d). If the expected payoff when both choose split, $\frac{1}{1-p}\left(\frac{1}{2} Y-e\right)=\frac{20}{1-p} \equiv x$, is strictly greater than that when at least one flip is chosen, $\frac{1}{2}\left(\frac{1}{1-p} Y-(1-\phi) Y\right)-e=\frac{1}{2}\left(\frac{100}{1-p}-30\right)-30 \equiv z$, then each player has a unique weakly

\footnotetext{
${ }^{6}$ In the first practice match, the continuation probability was $p=0$, and each subject was told to select split. In the second practice match, the continuation probability was again $p=0$, but each Blue was told to select split while each Red was told to select flip. The third and fourth practice matches had $p=0.5$ and $p=\frac{3}{4}$, respectively, and subjects were asked to choose split or flip on their own.
} 
dominant strategy to choose split when $p<p^{*}=\frac{1}{3}$ and choose flip when $p>p^{*}=\frac{1}{3}$. Though each game in Figure 1 has multiple Nash equilibria, applying standard game theoretic solution concepts (dominance solvability or Trembling Hand Perfection) yields an unique prediction of (split,split) under $p=0$ and (flip,flip) under $p=0.5$ or $p=0.75 .^{7}$ Past experimental work also suggests that subjects overwhelmingly go for the higher expected payoff in Hi-Lo games (e.g., see Bacharach 2006). Our first hypothesis follows.

\section{Hypothesis 1 (Choices)}

(a) We will observe more flips under $p=0.75$ than under $p=0$.

(b) We will observe more flips under $p=0.5$ than under $p=0$.

Our second hypothesis focuses on outcomes not individual choices, though the former are clearly derived from the later.

\section{Hypothesis 2 (Outcomes)}

(a) We will observe more conflict under $p=0.75$ than under $p=0$.

(b) We will observe more conflict under $p=0.5$ than under $p=0$.

We are also interested observing the patterns of choices by individual. Given Hypothesis 1, we predict the following.

Hypothesis 3 (Choices by subject) Most subjects will choose more flips under $p=0.75$ than under $p=0$ and more flips under $p=0.5$ than under $p=0$.

The first two hypotheses test the effect of the shadow of the future on Conflict. Given the structure of the interaction, it is natural to suppose each subject follows a cut-off rule with respect to $p$ when deciding to Settle or Fight. We are less interested in where this cut-off is for each subject, as it may differ from subject to subject due to variation risk preferences or

\footnotetext{
${ }^{7}$ With $p=0$, there are two pure strategy Nash equilibria: (split,split) and (flip,flip). With $p=0.5$ or $p=0.75$, there are three pure Nash equilibria: (flip,flip), (flip,split), and (split,flip). However, there is only one pure Nash equilibrium in each case if we eliminate the weakly dominated strategy for each player.
} 
other considerations, and more interested in whether or not the subjects are following such a cut-off rule. For this reason, we selected two values of the treatment variable to yield clear predictions via a clear payoff dominance (split under $p=0$ and flip under $p=0.75$ ). The other value, $p=0.5$, yields flipping under risk neutrality but might yield splitting under $p=0.5$ if subjects have sufficient risk aversion. Bearing this mind, we make no explicit hypothesis about the frequency of flips under $p=0.5$ compared to under $p=0.75$.

The last hypothesis is meant to "unpack" any verification or rejection of the first hypothesis. By looking more closely at the choices by individual we can discern what other factors, if any, figure prominently in the subjects' decision making. We also note that all hypotheses are falsifiable using standard statistical tests.

\subsection{Results}

Individual Choices. Table 2 reports the percent of flips by session and continuation probability. When pooling the data from all sessions, we see that, consistent with Hypothesis 1 , subjects choose flip more often under $p=0.75$ than under $p=0$ and more often under $p=0.5$ than under $p=0$. We conducted a series of (Pearson) Chi-square tests to test if the proportion of flips are the same under two given treatment values for $p$. As shown in Table 3 , we reject at very high significance levels the hypothesis that the proportion under $p=0$ and $p=0.75$ and under $p=0$ and $p=0.5$ are equal. Similar patterns are observed when looking at the data by session. Flips are more frequent in a statistically significant manner under $p=0.75$ and $p=0.5$ than under $p=0$.

We observe that the percent of flips under $p=0.5$ and $p=0.75$ are similar in the pooled data but with some variation across the sessions. While more flips occur under $p=0.75$ than $p=0.5$ in Session 1, the percent flips is nearly identical under those two treatment values in Sessions 2 and 3. The final column in Table 3 reports that the difference in flips is statistically significant in Session 1 but not in Sessions 2 and 3. Again, we note that this could be due to variation in subjects' risk preferences, with subjects in Session 1 exhibiting 
more risk aversion, on average, than those in Sessions 2 and 3.

Figure 2 displays the percent flips by match for each session. Each point captures the percent of subjects who chose flip in a given match and session. Matches have been grouped by continuation probability to facilitate comprehension. In each session, we observe a dramatic rise or drop in flips as the continuation probability changes from or to 0 , consistent with our shadow of the future argument.

The overall picture is that Hypotheses 1 is strongly confirmed: increasing the shadow of the future does increase the incidence of conflict. This pattern is observed when the data are pooled and when the data are separated by session. There is also some evidence that risk aversion may factor into some subjects' decision, especially for values of $p$ that are greater than but close to $p^{*}$. Another interpretation is that the direction of changes in the treatment variable produces confounding effects. For example, subjects in Session 1 proceeded in what we consider the easiest format, experiencing $p=0$ first and then experiencing "natural" increases in $p$; subjects in Session 2 proceeded in the more difficult format of highest $p$ first; and subjects in Session 3 proceeded in a combination structure that was not natural for learning.

Outcomes. Table 4 reports the distribution of outcomes by session and continuation probability. The easiest way to understand the table is to look at the percent of split-split outcomes; this outcome corresponds to Settlement while the other two outcomes correspond to Conflict. Consistent with Hypotheses 2, in the pooled data we observe the occurrence of Settlement to be lower under $p=0.75$ and $p=0.5$ than under $p=0$. The same pattern holds when looking by session, and it also matches that of individual choices. Chi-square tests (not shown) confirm the pattern. Conflict is much more likely when the shadow of the future is large $(p=0.5$ or $p=0.75)$ than when it is small $(p=0)$.

Choice Patterns. To evaluate Hypothesis 3, we classified subjects by their observed choices as reported in Table 5. The columns partition the behavior into disjoint choice patterns. Column (1) corresponds to the selection of flip in all matches of the session, 
column (2) corresponds to the selection of split in all matches, and so on. Columns (4) and (5), which are in bold lettering, correspond to the choice pattern predicted by Hypothesis 3. Column (4) is the strict variant such that all subjects included here chose strictly more flips under $p=0.75$ and $p=0.5$ than under $p=0$, while column (5) includes subjects who did not choose strictly more for both but did choose weakly more for both. The most common choice pattern corresponds to the behavior predicted in Hypothesis 3. By the strict measure, $54 \%$ (39 out of 72 ) of the subjects chose as predicted; by the weaker measure (combining columns (4) and (5)), the number increases to $65 \%$ (47 of 72). This choice pattern is also modal within each session, with roughly the same frequencies, i..e, the predicted pattern accounts for more than half in each session (not shown). Moreover, as shown in Table 5 , it is also the modal behavior for various subsamples by characteristic: male or female, undergraduate or graduate, exposed to economics or statistics or not exposed.

We observe a wide variation in choice behavior among the other subjects. For example, some $6 \%$ of all subjects (4 of 72) flipped most under $p=0,7 \%$ (5 of 72 ) never flipped, and 4\% (3 of 72 ) always flipped. The distribution of choice patterns is also similar across sessions (not shown). The various choice patterns may reflect preferences for risk, equity, or some combination of these or other concerns. ${ }^{8}$ Another possibility is that these other choice patterns reflect misunderstanding the decision making environment. Ruling this out is not possible, yet we gain some insight from the last question of the questionnaire, which asked, "Were you more likely or less likely to select FLIP as the continuation probability increased? Why or why not?" $72 \%$ (52 of 72 , line J, column 10) of the subjects answered yes and provided some explanation why (e.g., the "the chance of winning more money increased"), and of these subjects, $67 \%$ (35 of 52) acted consistently with the predicted behavior when using the strict criterion, and 75\% (39 of 52) did so when using the weak criterion. Only

\footnotetext{
${ }^{8}$ We note that these other choice patterns need not be classified as irrational. For example, a subject who cares about payoff equity and not her own payoff would choose split under each of the treatment values for $p$; an extremely risk averse subject would also choose split under each value for $p$; a very risk-loving subject who disliked extreme inequity might flip under $p=0$ but not $p=0.5$ or $p=0.75$; and a subject who wants a high expected payoff so long as it was not too inequitable might flip under $p=0.5$ but not under $p=0.75$ or $p=0$.
} 
$20 \%$ (4 of 20) of the other subjects did so as measured strictly; only $40 \%$ (8 of 20 ) did so when measured weakly. This is not a perfect measure of comprehension for many reasons. ${ }^{9}$ Nonetheless, it suggests that understanding the strategic setting led subjects to increase their flipping as the continuation probability increased. Indeed, no other characteristic, such as sex, exposure to statistics, and so on, seems to better predict their behavior; comprehension of the strategic environment best predicts whether or not a subject acted in accordance with our hypothesis. Altogether, this evidence suggests that a large majority of the subjects understood the basic "shadow of the future" logic, and this logic guided their behavior in the predicted manner.

\section{Conclusion}

We have argued and shown experimentally that a longer shadow of the future induces more conflict and less settlement. It is important to reiterate the conditions under which this effect can be expected to occur, both in order to be cognizant of the settings to which it applies and for possibly furthering understanding about the determinants of peace and conflict more generally. One condition for the effect to occur is that open conflict changes the future strategic positions of the adversaries differently than settlement (in the shadow of conflict) does. This condition is satisfied in many war, litigation, and other conflictual settings and is clearly empirically relevant.

The other condition under which the effect holds is that contracts on an enforcement variable like arming or litigation expenditures are not enforceable. That is, contracts can only be self-enforced through the choices on the enforcement variables made by the adversaries or that settlements only occur under the threat of conflict. This condition also appears to apply in many conflictual settings. For situations that may involve actual warfare, the condition implies a level of absence of trust (or, equivalently of institutions of governance) between

\footnotetext{
${ }^{9}$ Clearly not all subjects who said they were more likely to flip under the higher continuation probability did so. The question was asked after subjects completed their choices and had time to consider an optimal strategy. The very asking of the question may have prompted an answer more indicative of what the subject thought the experimenter wanted to hear.
} 
the adversaries that at best may lead to a protracted Cold War, which in our models would be represented by a series of settlements. Whether hot or cold, such wars are expensive, the former in terms of arming and destruction, the latter in terms of arming. Then, reducing the expense as well as the likelihood of war would amount to developing the trust or the institutions of governance that would make long term contracts on arming easier to enforce.

One way that trust could emerge has been extensively studied theoretically: through supergame strategies following the folk theorem. However, trust may be too elusive to achieve in many economic and political settings. Actual institutions of conflict management and of governance - independent courts and bureaucracies, checks and balances, other third parties - may be necessary to enforce long-term agreements. Such institutions are costly and take time to build, and as in the case of folk theorem settings we expect a longer value attached to the future to increase the incentives to invest in such costly institutions (for such a model, see Genicot and Skaperdas, 2002). That is, the settings - and the effect of the shadow of the future - that we have examined in this paper involve the absence of "property rights" that may be due to the absence of trust or institutions. Building such property rights would be more likely in conditions in which the future is highly valued. Thus, embedding the types of models we have examined here within more-encompassing ones that involve the endogenous emergence of trust and institutions would be a natural next step, both as means to further clarifying the effect of the shadow of the future and for improving understanding of why conflict occurs.

\section{APPENDIX}

\section{A Endogenous Enforcement}

In this Appendix we present an extension of the model from Section 3 to allow for endogenous enforcement levels. It is a dynamic contest model that draws on McBride and Skaperdas (2007). Contest models have been applied in cases of war, litigation, rent-seeking and other

settings (see Konrad, 2007, for an overview of the contests literature). The main comparative 
static result regarding the effect of the shadow of the future is shown to hold in this setting.

To allow for endogenous enforcement, we first need to specify how probabilities of winning depend on enforcement. We suppose that these probabilities depend on arming through the following additive contest success function (see Tullock, 1980, Hirshleifer, 1989, Clark and Riis, 1998):

$$
q_{i}\left(e_{A}, e_{B}\right)=\frac{e_{i}^{m}}{e_{A}^{m}+e_{B}^{m}} \text { where } i=A, B \text { and } m \in(0,1] .
$$

In each period, the sequence of moves by the two sides is the following:

1. Levels of enforcement, $e_{A}$ and $e_{B}$, are chosen simultaneously by the two agents.

2. The two agents bargain. Agent $A$ offers a division (subsidy) $S$ of the period's surplus to $B$. If $B$ accepts, then agent $B$ receives $S$, agent $A$ receives $Y-S$, and the next period repeats steps 1 and 2 . If $B$ rejects the offer, Conflict occurs with winner selected according to probabilities $q_{A}$ and $q_{B}$. The winner receives $\phi Y$ for the period and $Y$ in each period thereafter, whereas the loser receives 0 for the period and thereafter.

Note that when agent $A$ contemplates whether to offer a subsidy to agent $B$ or decide to engage in Conflict, the continuation payoff of agent $B$ would still be the one described in (2). Conditional on Settlement, the subsidy that would just induce $B$ not to go to Conflict is the following variation of (4):

$$
S^{*}\left(e_{A}, e_{B}\right)=q_{B}\left(e_{A}, e_{B}\right)[\phi(1-p)+p] Y+p e_{B}
$$

This subsidy is derived under the condition that the same level of enforcement, $\left(e_{A}, e_{B}\right)$, would be chosen in every future period as well as in the current period. Note how this subsidy to agent $B$ depends on its probability of winning, which is increasing in the enforcement level of the agent, as well as directly on the enforcement level of the agent, for under Settlement the agent would have to incur this cost of enforcement in every period.

The payoffs of the two agents under Settlement can now be calculated. Agent $A$ would receive in every period the total surplus minus the subsidy, $Y-S^{*}=Y-q_{B}\left(e_{A}, e_{B}\right)[\phi(1-$ 
$p)+p] Y-p e_{B}$, whereas in every period it would pay the cost of enforcement, $e_{A}$. We denote by $\left(e_{A}^{P}, e_{B}^{P}\right)$ the future levels of enforcement as part of a Markov perfect equilibrium, whereas the choices in the current period are denoted by $\left(e_{A}, e_{B}\right)$. Then, agent $A$ 's payoff is as follows

$$
V_{A}^{P}\left(e_{A}, e_{B}\right)=\frac{1}{1-p}\left\{Y-q_{B}\left(e_{A}, e_{B}\right)[\phi(1-p)+p] Y-p e_{B}^{P}-p e_{A}^{P}\right\}-e_{A} .
$$

Agent $A$ receives subsidy $S^{*}=q_{B}\left(e_{A}, e_{B}\right)[\phi(1-p)+p] Y+p e_{B}$ in every period and pays the cost of arming $\left(e_{B}\right)$ in every period as well. Then, agent $B$ 's payoff reduces to

$$
V_{B}^{P}\left(e_{A}^{P}, e_{B}^{P}\right)=\frac{1}{1-p}\left\{q_{B}\left(e_{A}, e_{B}\right)[\phi(1-p)+p] Y\right\}-e_{B} .
$$

The payoffs are not symmetric because $A$ is always the proposer and the subsidy offered is just the one that equates $B$ 's Settlement payoff with his expected payoff under Conflict.

The Markov perfect equilibrium strategies under Settlement are such that $e_{A}^{P}$ maximizes $V_{A}^{P}\left(e_{A}, e_{B}^{P}\right)$ whereas $e_{B}^{P}$ maximizes $V_{B}^{P}\left(e_{A}^{P}, e_{B}\right)$. To solve for these equilibrium strategies, first differentiate to obtain the first order conditions $\frac{\partial V_{A}^{p}}{\partial e_{A}}=0$ and $\frac{\partial V_{B}^{p}}{\partial e_{B}}=0$. Next, use

$$
\frac{\partial q_{B}}{\partial e_{A}}=\frac{-m e_{A}^{m-1} e_{B}^{m}}{\left(e_{A}^{m}+e_{B}^{m}\right)^{2}}, \frac{\partial q_{B}}{\partial e_{B}}=\frac{m e_{A}^{m} e_{B}^{m-1}}{\left(e_{A}^{m}+e_{B}^{m}\right)^{2}} .
$$

obtained from (7) and the first order conditions to show that

$$
e_{A}^{P}=e_{B}^{P}=\frac{m}{4} \frac{(\phi(1-p)+p)}{(1-p)} Y .
$$

Both sides choose the same level of arming despite the asymmetry of payoffs in (9) and (10) because the cost of arming is the same and what becomes effectively contestable is the discounted total surplus under Conflict $\left(\frac{(\phi(1-p)+p)}{(1-p)} Y\right)$.

Note the strong positive dependence of enforcement on the discount factor through the effect of the discounted total surplus under Conflict $\left(\frac{(\phi(1-p)+p)}{(1-p)} Y\right)$. For example, supposing $\phi=0.5$, an increase in the discount factor from 0.9 to 0.95 more than doubles the term $\frac{(\phi(1-p)+p)}{(1-p)}$ from 9.5 to 19.5. As we've seen in section 3 (see (6)), a higher discount factor, as well higher levels of (fixed) arming, increases the likelihood of Conflict. With endogenous enforcement levels, a higher discount factor increases equilibrium enforcement, and the set 
of parameters for which Conflict becomes an equilibrium must increase compared to the case with exogenous enforcement.

Before deriving such a set of parameters, we consider the case of Conflict. The payoffs under Conflict are the following:

$$
V_{i}^{W}\left(e_{A}, e_{B}\right)=q_{i}\left(e_{A}, e_{B}\right) \frac{(\phi(1-p)+p)}{(1-p)} Y-e_{i}, i=A, B
$$

It is straightforward to show that equilibrium enforcement is not just symmetric but the same as under Settlement:

$$
e_{A}^{C}=e_{B}^{C}=\frac{m}{4} \frac{(\phi(1-p)+p)}{(1-p)} Y=e_{i}^{S}, i \in A, B
$$

The reason for the identical levels of enforcement under both Settlement and Conflict is that, even under Settlement, the determinant of equilibrium enforcement is the payoff under Conflict, and the latter determines the disagreement point in bargaining for the two sides. Under both Settlement and Conflict the relevant portion of $B$ 's payoff that can be influenced by its choice of arming is $q_{B}\left(e_{A}, e_{B}\right) \frac{(\phi(1-p)+p)}{(1-p)} Y$, whereas for $A$ it is either $-q_{B}\left(e_{A}, e_{B}\right) \frac{(\phi(1-p)+p)}{(1-p)} Y$ (for the case of Settlement) or $q_{A}\left(e_{A}, e_{B}\right) \frac{(\phi(1-p)+p)}{(1-p)} Y$ (for the case of Conflict) which equals $\left(1-q_{B}\left(e_{A}, e_{B}\right)\right) \frac{(\phi(1-p)+p)}{(1-p)} Y$, both of which leads to the same marginal incentives in the choice of enforcement.

The set of parameters under which either Settlement or Conflict prevail can be derived by substituting the endogenous enforcement levels from (14) or (6). Settlement occurs when

$$
\frac{p m(\phi(1-p)+p)}{2(1-p)^{2}(1-\phi)} \leq 1
$$

From (15) we conclude that Conflict is more likely and Settlement less likely when (i) the effectiveness of conflict as represented by $m$ is high; (ii) the higher is the discount factor $p$; and (iii) the less destructive Conflict is (or, the higher is $\phi$ ). The effect of the discount factor is, if anything, stronger here because as we mentioned above a higher discount factor not only increases the discounted value of the future cost of arming under Settlement but also increases the equilibrium level of arming. 


\section{B An Alternative Litigation Setting}

The models of section 3 and Appendix A could be interpreted as involving two parties that are involved in a long-term legal but potentially decisive dispute. For example, they might have competing claims on a productive asset which they can exploit jointly under a series of short-term agreements (that is, under the Settlement outcome), backed by their respective litigation expenditures, or they could resolve once-and-for-all in court (under the Conflict outcome). In this Appendix, we examine a variation of the model of section 3 with one longterm agent potentially facing a series of short-term agent who could sue the long-term agent for damages. The main purpose of this model is to show how the main comparative-static result of the effect of the shadow of the future readily extends to such settings.

Consider a long-term agent $A$, with an indefinite horizon, who faces in each period a short-term potential challenger $b$ (each lasting one period) who could sue agent $A$ for the rights to a one-time payment of $Y$. To sue $A$ a challenger would have to incur a fixed cost of $e_{b}>0$. If no court decision has taken place in the past, let $q_{o}$ denote the probability of winning in court of agent $A$, with $1-q_{o}$ thus representing the challenger's probability of winning. We suppose that $q_{o} \geq 1 / 2$ (so that $A$ can be thought of as having a better initial property right than the challengers. If sued, agent $A$ incurs a legal cost $e_{A}>0$ regardless of whether the two sides go to court or not; this cost can be thought of as the cost of hiring a legal team that would help $A$ with the possible settlement and pre-trial costs but also preparing for the eventuality of going to court. If the two sides were to go to court, both would incur an additional cost $c>0$.

As in the model of section 1, $A$ can make a Settlement offer to $b$, which the latter accepts or rejects. Once $b$ has sued (and has paid cost $e_{b}$ ), his expected payoff of going to court is

$$
U_{b}^{c}\left(q_{o}\right)=\left(1-q_{o}\right) Y-c
$$

$A$ could offer a payment $S_{o}=\left(1-q_{o}\right) Y-c$ to $b$, which $b$ could accept, and thus settle or she could offer something less, which $b$ would reject, resulting in the two sides going to 
court. Let us now consider what could occur under the two possibilities.

First, if $A$ were to make the payment $S_{o}$ and then continue doing so to each future challenger, her payoff would be ${ }^{10}$

$$
\begin{aligned}
V_{A}^{s}\left(q_{o}\right) & =Y-S_{o}+\sum_{t=1}^{\infty} p^{t}\left(Y-S_{o}-e_{A}\right) \\
& =q_{o} Y+c+\sum_{t=1}^{\infty} p^{t}\left(q_{o} Y+c-e_{A}\right)=\frac{q_{o} Y+c-p e_{A}}{1-p} .
\end{aligned}
$$

Note that for the challenger in each period to choose to sue, it must be the case that the settlement payment received from $A$ is higher than the cost of suing, or

$$
S_{o}=\left(1-q_{o}\right) Y-c \geq e_{b}
$$

We suppose that this condition is satisfied for the remainder of this Appendix.

Going to court yields more complicated long-term outcomes. If the court decides in favor of $A$, then all future challengers $b$ face worse odds of winning in the future. Let $q_{h}\left(>q_{o}\right)$ denote $A$ 's future probability winning in court in the future. Conversely, if $A$ loses in court following an initial challenge, her future probability of winning decreases to $q_{l}\left(<q_{o}\right)$. To determine the expected payoffs of going to court, we thus need to determine the expected payoffs in the case of a court win and and in the case of a court loss.

Suppose that in the case of a win, $A$ would not be challenged in the future. (This could be assured if $e_{b}>\left(1-q_{h}\right) Y-c$, the latter being the expected payoff of a challenger. $)^{11}$ Then, the value of having a probability of winning of $q_{h}$ from next period onward would be $\frac{Y}{1-p}$.

In the case of a loss, there will always be a challenge given that $\left(1-q_{l}\right) Y-c>\left(1-q_{o}\right) Y-c$ which by assumption is greater or equal than $e_{b}$. Then, there is the possibility of settlement and that of going to court, again, in that case. Suppose first the case of settlement. Each challenger $b$ would receive in each period a settlement payment $S_{l}=\left(1-q_{l}\right) Y-c$, with the

\footnotetext{
${ }^{10}$ Note that this value does not include the cost of $e_{A}$ which is considered to have been already paid. We continue the same practice in denoting values functions net of this cost below.

${ }^{11}$ If there were to be future challenges, similar results would be obtained.
} 
expected payoff of $A$, denoted $V_{B}^{s}\left(q_{l}\right)=\frac{Y-S_{l}-e_{A}}{1-p}=\frac{q_{l} Y+c-e_{A}}{1-p}$. Therefore, if there is settlement when $A$ loses after going to court the first time, the expected payoff of going to court is

$$
V_{A}^{C s}\left(q_{o}\right)=q_{o} Y-c+q_{o} p \frac{Y}{1-p}+\left(1-q_{o}\right) p \frac{q_{l} Y+c-e_{A}}{1-p} .
$$

In that case, $A$ will choose to go to Court if and only if ${ }^{12}$

$$
\begin{aligned}
V_{A}^{s}\left(q_{o}\right) & <V_{A}^{C s}\left(q_{o}\right) \Rightarrow \\
\frac{q_{o} Y+c-p e_{A}}{1-p} & <q_{o} Y-c+q_{o} p \frac{Y}{1-p}+\left(1-q_{o}\right) p \frac{q_{l} Y+c-e_{A}}{1-p} \Rightarrow \\
\left(2-p\left(2-q_{o}\right)\right) c & <p\left(1-q_{o}\right) q_{l} Y+q_{o} e_{A} .
\end{aligned}
$$

Because both sides of this inequality are positive, the range of parameters that would result in going to court is larger the higher is $p$. In other words, the effect of the shadow of the future holds in this setting, a setting that involves less decisive conflict than that of the models in section 3 and appendix A. We also note, but do not have space to show formally here, that the effect remains under still richer variations of this setting. For example, if $A$ 's win probability, once it drops after a loss may later rise again after a win, then the shadow of the future effect still operates. We thus see that the shadow of the future looms large across many settings.

\section{References}

[1] Abbink, Klaus and Jordi Brandts, 2009, "Political Autonomy and Independence: Theory and Experimental Evidence," working paper, January.

[2] Acemoglu, Daron, and James Robinson, 2000, "Why did the West Extend the Franchise? Democracy, Inequality, and Growth in Historical Perspective," Quarterly Journal of Economics, 115, 1167-1199.

[3] Bacharach, Michael, 2006, Beyond Individual Choice: Teams and Frames in Game Theory, Princeton: Princeton University Press.

[4] Bester, Helmut and Kai Konrad, 2004, "Delay in Contests," European Economic Review 48 (5), 1169-1178.

[5] Bester, Helmut and Kai Konrad, 2005, "Easy targets and the timing of conflict," Journal of Theoretical Politics, 17 (2): 199-215.

\footnotetext{
${ }^{12}$ We suppose that Settlement occurs when the two payoffs are equal.
} 
[6] Bester, Helmut and Karl Warneryd, 2006. "Conflict and the Social Contract," Scandinavian Journal of Economics, 108(2), 231-249.

[7] Brito, Dagobert and Michael Intriligator, 1985, "Conflict, War and Redistribution," American Political Science Review, 79 (4), 943-957.

[8] Buchanan, James, 1989, Notes on Irrelevant Externalities, Enforcement Costs, and the Atrophy of Property Rights. In: Tollison, R. and Vanberg, V. (eds) Explorations Into Constitutional Economics. College Station: Texas A\&M University Press.

[9] Budd, Christopher, Christopher Harris, and John Vickers, 1993, "A Model of the Evolution of Duopoly: Does the Asymmetry between Firms Tend to Increase or Decrease?" Review of Economic Studies, 60, 543-573.

[10] Clark, Derek. and Christian Riis, 1998, "Contest Success Functions: An Extension," Economic Theory, 11, 201-204.

[11] Collier, Paul, Elliott V.L., Hegre Havard, Hoeffler, Anke, Reynal-Querol, Marta, and Sambanis, Nicholas, Breaking the Conflict Trap; Civil War and Development Policy, (World Bank Policy Report), 2003, Washington, DC: World Bank and Oxford University Press.

[12] Dal Bó, Pedro, 2005, "Cooperation under the Shadow of the Future: Experimental Evidence from Infinitely Repeated Games," American Economic Review, 95 (5), 15911604.

[13] Durham, Yvonne, Jack Hirshleifer, and Vernon L. Smith, 1998. "Do the Rich Get Richer and the Poor Poorer? Experimental Tests of a Model of Power," American Economic Review, September, 88(4), 970-83.

[14] Esteban, Joan and Debraj Ray, 2008, "On the Salience of Ethnic Conflict," American Economic Review, December, 98(5), 2185-2202.

[15] Esteban, Joan and Debraj Ray,1999. "Conflict and Distribution," Journal of Economic Theory, 87(2), 379-415.

[16] Farmer, Amy and Pecorino, Paul, 1999, "Legal Expenditure as a Rent Seeking Game", Public Choice, September, 100, 271-288.

[17] Fearon, James, 1995, "Rationalist Explanations for War," International Organization, $49(3), 379-414$.

[18] Fearon, James, and David D. Laitin, 2003, "Ethnicity, Insurgency, and Civil War." American Political Science Review 97(1), 75-90.

[19] Fudenberg, Drew, and Jean Tirole, 1996, Game Theory, Cambridge: MIT Press.

[20] Garfinkel, Michelle and Stergios Skaperdas, 2000, "Conflict Without Misperception or Incomplete Information: How the Future Matters," Journal of Conflict Resolution, 44(6), 793-807.

[21] Genicot, Garance and Stergios Skaperdas, 2002, "Investing in Conflict Management," Journal of Conflict Resolution, 46, 154-170.

[22] Gradstein, Mark, 2004, "Governance and Growth," Journal of Development Economics, 73, 505-518. 
[23] Greif, Avner, 2006, Institutions and the Path to the Modern Economy: Lessons from Medieval Trade, New York: Cambridge University Press.

[24] Grossman, Sanford and Oliver Hart, 1986, "The Costs and Benefits of Ownership: A Theory of Vertical and Lateral Integration," Journal of Political Economy, 84, 691719.

[25] Harris, Christopher and John Vickers, 1987, "Racing with Uncertainty," Review of Economics Studies, 54, 1-21.

[26] Hay, B. and Spier, K, 1998 Settlement of Litigation. In: Newman, P. (ed.) The New Palgrave Dictionary of Economics and the Law, New York: Stockton Press.

[27] Hirshleifer, Jack, 1989, "Conflict and Rent-seeking Success Functions: Ratio Vs. Difference Models Of Relative Success." Public Choice, 63(2), 101-12.

[28] Hirshleifer, Jack, 1991, "The Paradox of Power," Economics and Politics, 3(3), 177200.

[29] Hirshleifer, Jack and Evan Osborne, 2001, "Truth, Effort and the Legal Battle", Public Choice, 108, 169-195.

[30] Jackson, Matthew O. and Massimo Morelli, 2008, "Strategic Militarization, Deterrence and Wars," September, working paper.

[31] Joll, James, 1992, The Origins of the First World War, 2nd Edition, New York: Longman.

[32] Konrad, Kai A., 2007, Strategy in Contests - An Introduction, monograph manuscript.

[33] McBride, Michael, 2005, "Crises, Reforms, and Regime Persistence in sub-Saharan Africa," European Journal of Political Economy 21 (3): 688-707.

[34] McBride, Michael and Stergios Skaperdas, 2007, "Explaining Conflict in LowIncome Countries: Incomplete Contracting in the Shadow of the Future," in M. Gradstein and K.A. Konrad, (eds.), Institutions and Norms in Economic Development, 141161, Cambridge, MA: MIT Press.

[35] McNeill, William, 1982, The Pursuit of Power, Chicago: University of Chicago Press.

[36] Mehlum, Halvor and Karl Moene, 2006, "Fighting Against the Odds," Economics of Governance, Economics of Governance, 7(1), 75-8\%,.

[37] Powell, Robert, 1993, "Guns, Butter, and Anarchy," American Political Science Review, March, 87(1), 115-132.

[38] Powell, Robert, 2006, "War as a Commitment Problem," International Organization.

[39] Robson, Alexander and Skaperdas, Stergios, 2008, "Costly Enforcement of Property Rights and the Coase Theorem," Economic Theory, July, 36(1), 109-128

[40] Sambanis, Nicholas, 2004, "Using Case Studies to Expand Economic Models of Civil War," Perspectives on Politics, 2(2), 259-279.

[41] Skaperdas, Stergios, 2006, "Bargaining vs. Fighting," Defense and Peace Economics, December, 17(6), 657-676. 
[42] Skaperdas, Stergios and Constantinos Syropoulos, 1996, "Can the Shadow of the Future Harm Cooperation," Journal of Economic Behavior and Organization, 29, 355372.

[43] Tilly, Charles, 1992, Coercion, Capital and European States, New York: Blackwell.

[44] Tullock, Gordon, 1980, "Efficient Rent Seeking." In Toward a Theory of the Rent Seeking Society, edited by James M. Buchanan, Robert D. Tollison, and Gordon Tullock, College Station: Texas A\&M University Press, 3-15. 


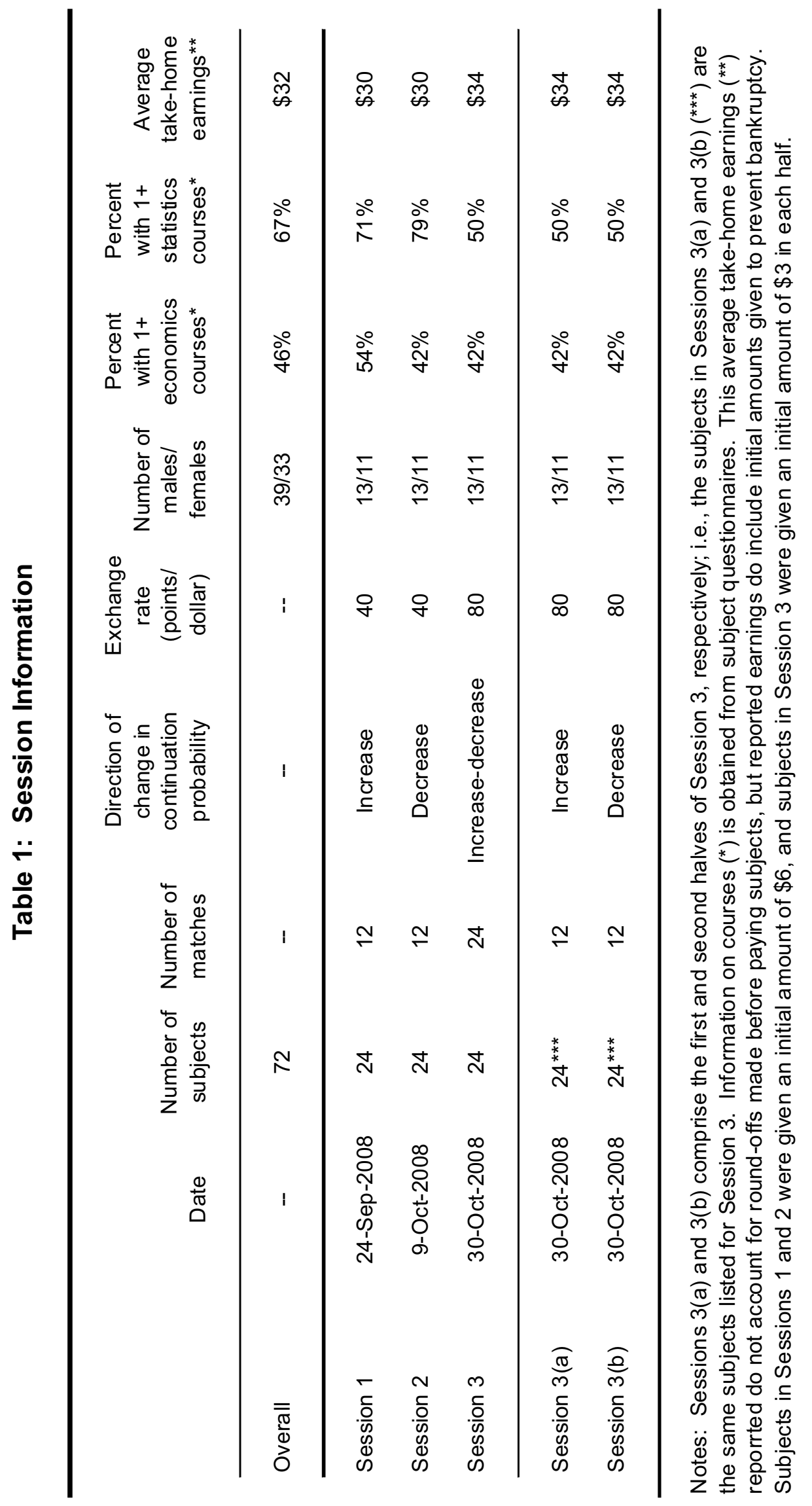



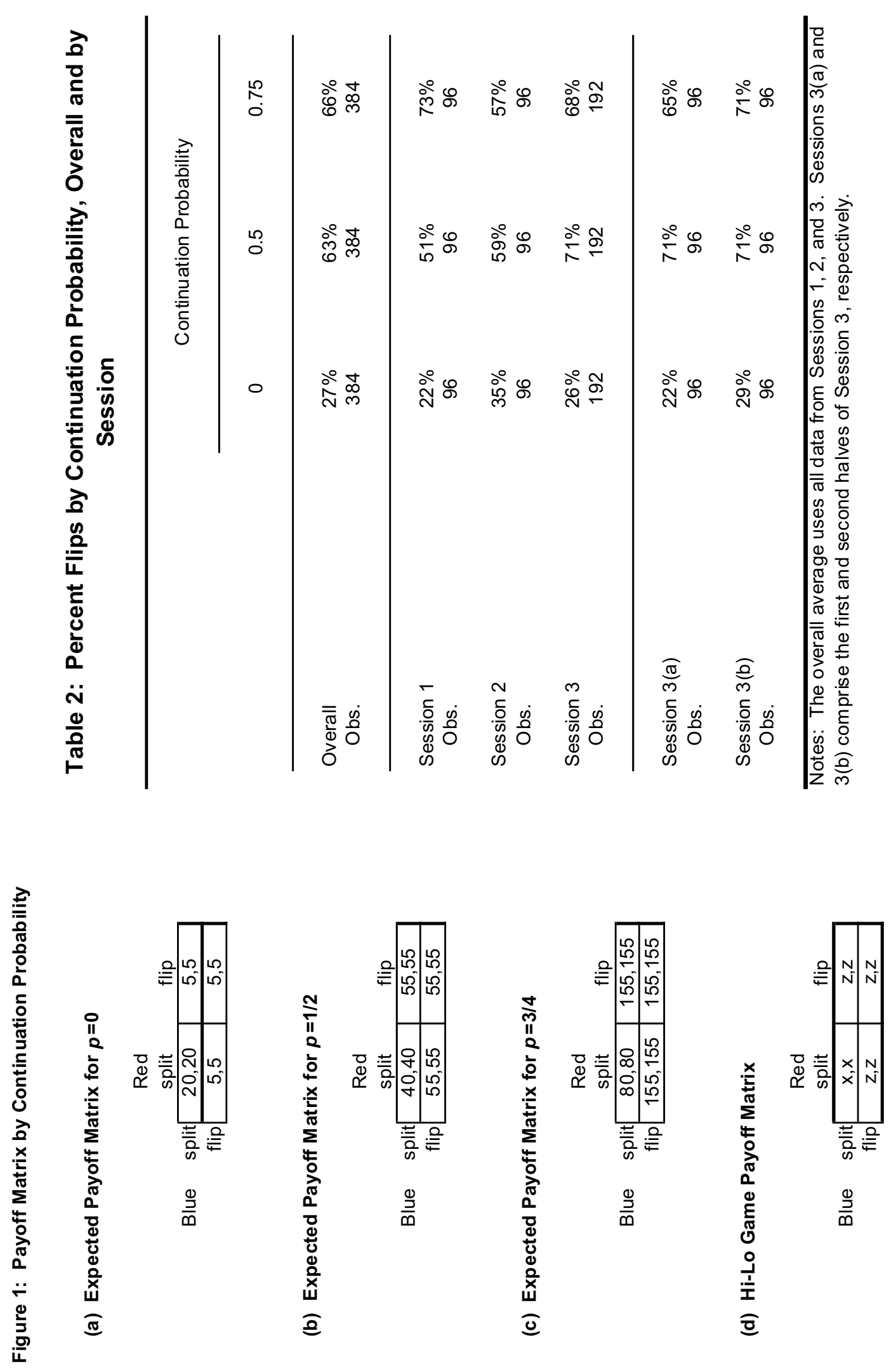
Table 3: Chi-square Test Statistics for Hypothesis 1, Overall and by Session

Hypothesis 1

\begin{tabular}{|c|c|c|c|}
\hline & $\begin{array}{l}1(\mathrm{a}) \\
\text { Proportion of flips } \\
\text { under } p=0 \text { equals } \\
\text { proportion under } \\
\quad p=0.75\end{array}$ & $\begin{array}{l}1(b) \\
\text { Proportion of flips } \\
\text { under } p=0 \text { equals } \\
\text { proportion under } \\
\quad p=0.5\end{array}$ & $\begin{array}{c}\text { Proportion of flips } \\
\text { under } p=0.5 \text { equals } \\
\text { proportion under } \\
p=0.75\end{array}$ \\
\hline $\begin{array}{l}\text { Overall } \\
\qquad p \text {-value }\end{array}$ & $\begin{array}{c}119.261 \\
<0.01\end{array}$ & $\begin{array}{c}100.168 \\
<0.01\end{array}$ & $\begin{array}{c}0.964 \\
0.33\end{array}$ \\
\hline $\begin{array}{r}\text { Session } 1 \\
p \text {-value }\end{array}$ & $\begin{array}{l}50.157 \\
<0.01\end{array}$ & $\begin{array}{l}17.626 \\
<0.01\end{array}$ & $\begin{array}{l}9.747 \\
<0.01\end{array}$ \\
\hline $\begin{array}{r}\text { Session } 2 \\
p \text {-value }\end{array}$ & $\begin{array}{l}9.237 \\
<0.01\end{array}$ & $\begin{array}{l}11.051 \\
<0.01\end{array}$ & $\begin{array}{c}0.086 \\
0.79\end{array}$ \\
\hline $\begin{array}{r}\text { Session } 3 \\
p \text {-value }\end{array}$ & $\begin{array}{l}68.659 \\
<0.01\end{array}$ & $\begin{array}{l}78.949 \\
<0.01\end{array}$ & $\begin{array}{c}0.440 \\
0.51\end{array}$ \\
\hline $\begin{array}{c}\text { Session } 3(a) \\
p \text {-value }\end{array}$ & $\begin{array}{l}35.675 \\
<0.01\end{array}$ & $\begin{array}{l}46.267 \\
<0.01\end{array}$ & $\begin{array}{l}0.858 \\
0.35\end{array}$ \\
\hline $\begin{array}{c}\text { Session } 3(b) \\
p \text {-value }\end{array}$ & $\begin{array}{l}33.333 \\
<0.01\end{array}$ & $\begin{array}{l}33.333 \\
<0.01\end{array}$ & $\begin{array}{c}0.000 \\
1.00\end{array}$ \\
\hline
\end{tabular}

Notes: The overall average uses all data from Sessions 1, 2, and 3. 
Figure 2(a): Percent Flips by Match, Session 1

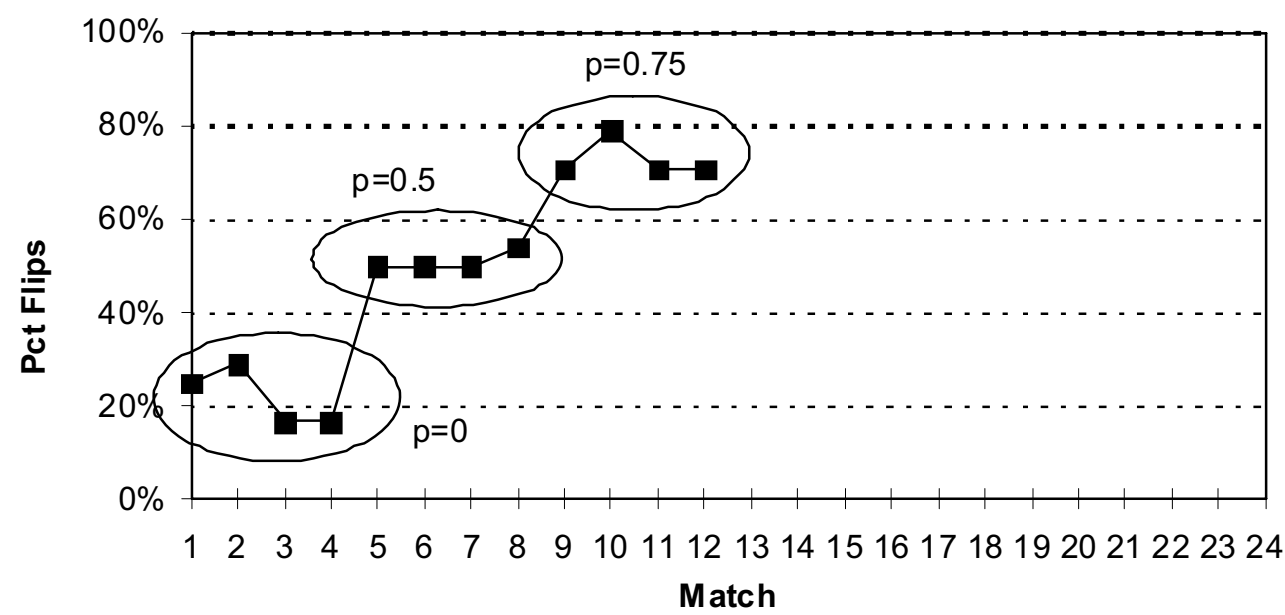

Figure 2(b): Percent Flips by Match, Session 2

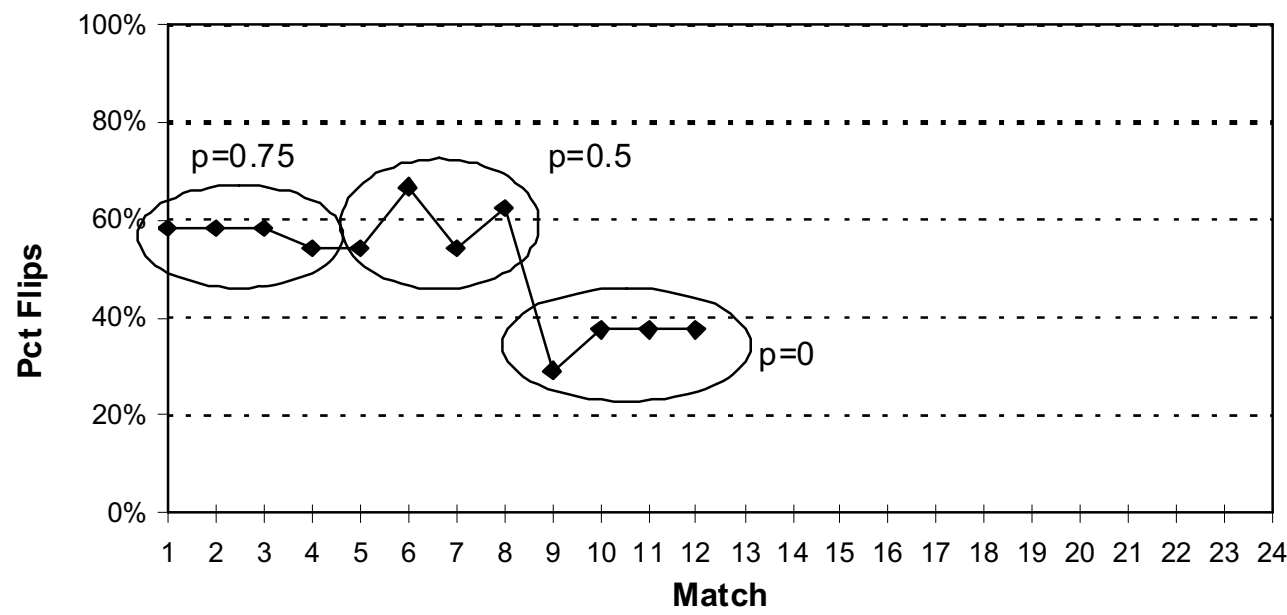

Figure 2(c): Percent Flips by Match, Session 3

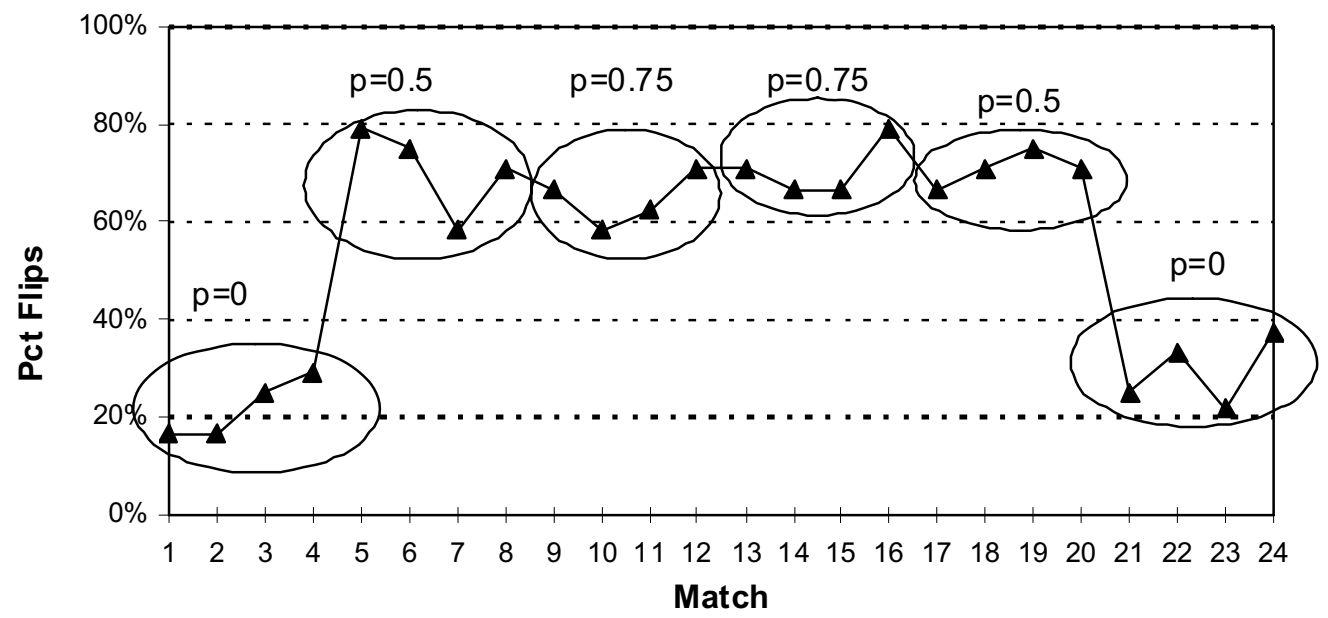


Table 4: Percent Outcomes by Continuation Probability, Overall and by Session

\begin{tabular}{|c|c|c|c|}
\hline & \multicolumn{3}{|c|}{ Continuation Probability } \\
\hline & 0 & 0.5 & 0.75 \\
\hline \multicolumn{4}{|l|}{ Overall } \\
\hline Flip-flip & $5 \%$ & $39 \%$ & $41 \%$ \\
\hline Flip-split & $45 \%$ & $49 \%$ & $51 \%$ \\
\hline Split-split & $51 \%$ & $13 \%$ & $8 \%$ \\
\hline \multicolumn{4}{|l|}{ Session 1} \\
\hline Flip-flip & $0 \%$ & $23 \%$ & $52 \%$ \\
\hline Flip-split & $44 \%$ & $56 \%$ & $42 \%$ \\
\hline Split-split & $56 \%$ & $21 \%$ & $6 \%$ \\
\hline \multicolumn{4}{|l|}{ Session 2} \\
\hline Flip-flip & $8 \%$ & $31 \%$ & $27 \%$ \\
\hline Flip-split & $54 \%$ & $56 \%$ & $60 \%$ \\
\hline Split-split & $38 \%$ & $13 \%$ & $13 \%$ \\
\hline \multicolumn{4}{|l|}{ Session 3} \\
\hline Flip-flip & $5 \%$ & $50 \%$ & $43 \%$ \\
\hline Flip-split & $41 \%$ & $42 \%$ & $50 \%$ \\
\hline Split-split & $54 \%$ & $8 \%$ & $7 \%$ \\
\hline \multicolumn{4}{|l|}{ Session 3(a) } \\
\hline Flip-flip & $4 \%$ & $52 \%$ & $40 \%$ \\
\hline Flip-split & $35 \%$ & $38 \%$ & $50 \%$ \\
\hline Split-split & $60 \%$ & $10 \%$ & $10 \%$ \\
\hline \multicolumn{4}{|l|}{ Session 3(b) } \\
\hline Flip-flip & $6 \%$ & $48 \%$ & $46 \%$ \\
\hline Flip-split & $46 \%$ & $46 \%$ & $50 \%$ \\
\hline Split-split & $48 \%$ & $6 \%$ & $4 \%$ \\
\hline
\end{tabular}




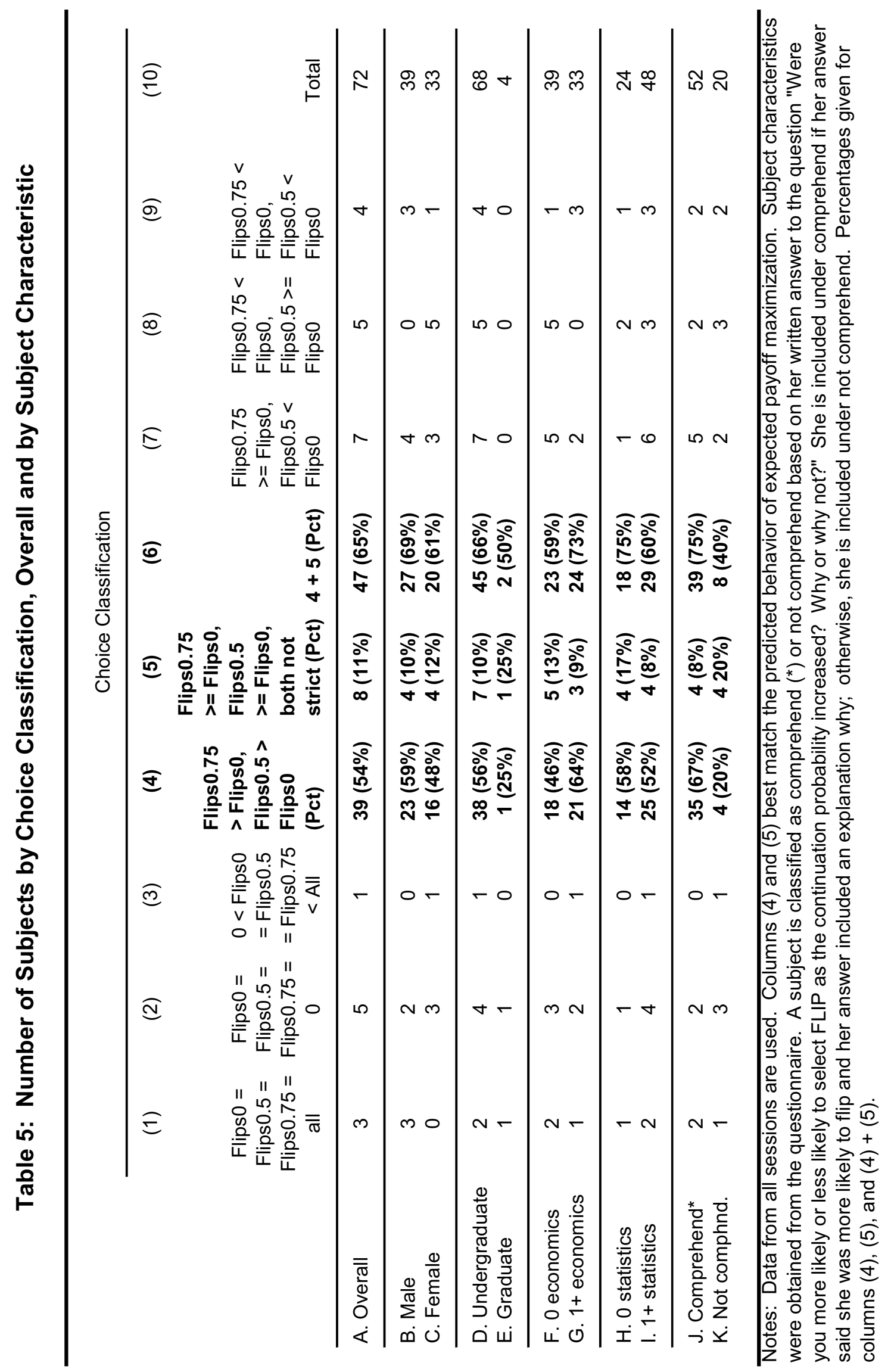

